\title{
RESISTENCIAS, REGULACIONES Y ALTERNATIVAS: DE LAS ESTRATEGIAS EMPRESARIALES A LAS PROPUESTAS DE TRANSICIÓN
}

\author{
Pedro Ramiro \\ Coordinador del Observatorio de Multinacionales en América Latina \\ (OMAL-Paz con Dignidad)
}

DOI: $10.1387 /$ lan-harremanak.16104

\section{ABSTRACT}

En el marco de la mayor crisis económica, ecológica y social de la historia del capitalismo global, las empresas transnacionales están utilizando toda una serie de estrategias corporativas para presentarse ante el conjunto de la sociedad como los actores principales para la recuperación socioeconómica. Este reposicionamiento de la imagen empresarial pasa, entre otros factores, por una combinación de las técnicas de comunicación y marketing con la cooptación de las instituciones gubernamentales y la asunción de la responsabilidad social corporativa como simbolo de autorregulación empresarial. Como analizaremos en el presente artículo, frente a ello, con el fin de avanzar hacia modelos de desarrollo post-capitalistas, las organizaciones y movimientos de la sociedad civil están desarrollando nuevos discursos, iniciativas contrahegemónicas y propuestas de transición que van caminando con una triple perspectiva: de resistencia, frenando los impactos negativos de la expansión de las empresas transnacionales; de regulación, proponiendo mecanismos de control que sirvan para situar los derechos de las personas y los pueblos por encima de la lex mercatoria; y de alternativas, llevando a la práctica propuestas concretas que vayan disputando parcelas de autonomía y soberanía económica a las grandes corporaciones.

Palabras clave: empresas transnacionales, lex mercatoria, responsabilidad social corporativa, propuestas alternativas. 
In the setting of the greatest economic, ecological and social crisis in the history of global capitalism, transnational companies are using a whole series of corporate strategies to present themselves to society as a whole as the principal players in the economic recovery. This repositioning of the corporate image involves, among other factors, a combination of advertising and marketing techniques with the co-opting of government institutions and the assumption of corporate social responsibility as a symbol of business self-regulation. As discussed in this article, in the face of this, with the aim of moving forward towards post-capitalist models of development, civil society organisations and movements are developing new anti-hegemonic discourses, initiatives and proposals for transition based on a triple perspective: one of resistance, putting a brake on the negative impacts of the expansion of transnational corporations; of regulation, proposing control mechanisms that serve to place the rights of people and groups of people above lex mercatoria; and of alternatives, implementing specific proposals that compete with the big corporations for areas of economic autonomy and sovereignty.

Keywords: transnational corporations, lex mercatoria, corporate social responsibility, alternative proposals.

Kapitalismo globalaren historiak izan duen krisi ekonomiko, ekologiko eta sozial handienaren esparruan, enpresa transnazionalak estrategia korporatibo ugari erabiltzen ari dira, gizarteari erakutsi nahian eurak direla gure egoera sozio-ekonomikoa lehengoratzeko eragile nagusiak. Irudi enpresarialak egin duen birkokapen honetan, hainbat faktorek hartu dute parte: batetik, komunikazio eta marketinerako teknikak gobernu erakundeen kooptazioarekin uztartu dituzte, eta bestetik, gizarte erantzukizun korporatiboa onartu dute enpresa autoerregulatzeko sinbolo gisa. Artikulu honetan aztertuko dugun moduan, horri aurre egin ahal izateko eta garapen eredu post-kapitalistetarantz joateko, gizarte zibileko erakunde zein mugimenduak lehengoak ez bezalako arrazoibideak, ekimen kontrahegemonikoak eta trantsizio proposamenak sortzen ari dira, ikuspegi hirukoitzarekin aurrera doazenak: lehenik, aurre egitekoa, enpresa transnazionalen hedapenaren ondorio negatiboak murriztuz; bigarrenik, erregulaziozkoa, pertsonen zein herrien eskubideak lex mercatoriaren gainetik jartzeko baliagarriak izango diren kontrol mekanismoak proposatuz; eta hirugarrenik, proposamen alternatiboena, autonomia eta burujabetasun ekonomikorako tarteak eskuratzeko korporazio handiekin lehiatzeko proposamen zehatzak praktikara eramanez.

Hitz gakoak: enpresa transnazionalak, lex mercatoria, gizarte erantzukizun korporatiboa, proposamen alternatiboak. 


\section{Introducción}

Con la expansión del capitalismo global y el aumento del poder de las grandes corporaciones, se han multiplicado por todo el planeta las luchas sociales que ponen en cuestión la centralidad de las empresas transnacionales en el modelo de desarrollo. En las últimas décadas, confrontando la visión hegemónica que sitúa al crecimiento económico y al sector privado ${ }^{1}$ como pilares del progreso y el bienestar para toda la sociedad, han ido surgiendo numerosos procesos de resistencia para enfrentar la creciente mercantilización y privatización de cada vez más esferas de nuestra vida. Junto con estas experiencias, impulsadas en buena medida por organizaciones de la sociedad civil y movimientos sociales emancipadores, han cristalizado también distintos paradigmas y marcos de referencia alternativos a la modernidad capitalista (Fernández, 2015). De ellos se derivan toda una serie de propuestas de transición hacia economías y sociedades post-capitalistas que, como analizaremos en el presente artículo, están avanzando en paralelo entre la formulación de mecanismos de regulación y la construcción de alternativas económicas al modelo neoliberal.

Por su parte, las empresas transnacionales, ante un contexto de crisis global marcado por la necesidad de intensificar sus mecanismos de acumulación por desposesión (Harvey, 2004) y continuar ampliando sus negocios a nuevos sectores y mercados para sostener sus propias lógicas de crecimiento y beneficio constantes, han dispuesto una batería de estrategias corporativas para modificar la percepción que de ellas tiene buena parte de la sociedad. Este reposicionamiento de la imagen empresarial pasa, entre otros elementos, por una combinación de las técnicas de comunicación y marketing con una extensa producción discursiva, todo ello con el objetivo de contribuir a que estas compañías puedan presentarse ante la opinión pública como los actores principales para hacer posible la recuperación económica y salir de la crisis (Ramiro, 2014).

${ }^{1}$ El término sector privado suele emplearse habitualmente en la literatura oficial de los organismos multilaterales y las instituciones económico-financieras internacionales para hacer referencia a las empresas transnacionales. Para un análisis más detallado de este concepto, véase: RAMIRO, Pedro (2012): «Sector privado», en HERNÁNDEZ, Juan; GONZÁLEZ, Erika y RAMIRO, Pedro (eds.), Diccionario crítico de empresas transnacionales, Barcelona, Icaria. 
Hoy, cuando el poder de las grandes corporaciones y la presión de la lex mercatoria se hacen sentir con fuerza sobre las personas y los pueblos - poniendo, como en el caso de Grecia en 2015, los intereses del capital transnacional por encima de los procedimientos básicos de la democracia-, sobre el medio natural y las condiciones que hacen posible la vida en el planeta, se hace necesario cuestionar el sistema socioeconómico dominante y, al mismo tiempo, apostar por la articulación de otros modelos de desarrollo que tengan como eje la justicia social y ambiental. En ese marco, frente a lo que se ha dado en llamar la arquitectura jurídica de la impunidad, se están proponiendo nuevos marcos regulatorios y propuestas alternativas para situar los derechos de las personas y de la naturaleza, como mínimo, al mismo nivel que los de las empresas transnacionales (Hernández y Ramiro, 2015). En esa línea están caminando ya distintas iniciativas que están siendo formuladas y llevadas a la práctica por organizaciones sociales e incluso instancias de gobierno —en el Estado español, por el momento, a nivel municipal; en otros países, especialmente en América Latina, también a escala estatal-, constituyéndose como vías para ir desmantelando el poder de las grandes corporaciones e ir construyendo otros modelos de economía y sociedad.

\section{Estrategias empresariales en la lex mercatoria}

El hecho de que actualmente las grandes corporaciones dispongan de un gran poder económico, político, jurídico y cultural tiene que ver con la propia evolución del capitalismo global en los dos últimos siglos. Así, el avance de las políticas neoliberales y de los procesos de globalización económica y financiera han llevado a que, en la actualidad, las empresas transnacionales puedan eludir prácticamente cualquier control, tanto público como ciudadano, ya que el poder económico-financiero que poseen, su carácter transnacional, su versatilidad jurídica y sus complejas estructuras societarias les permiten evadir las diferentes regulaciones y leyes nacionales e internacionales (Teitelbaum, 2010). «Vivimos bajo la tiranía mundial del capital globalizado», ha indicado Jean Ziegler, relator especial de Naciones Unidas para el derecho a la alimentación entre 2000 y 2008 y hoy vicepresidente del Comité Asesor del Consejo de Derechos Humanos de la ONU, "de una oligarquía formada por sociedades transcontinentales cuyo unico principio es la maximización del beneficio, que concentran en sus manos el poder político y económico» ${ }^{2}$.

En la lex mercatoria, mientras blindan sus derechos a través de un ordenamiento jurídico global fundamentado en la amplia producción normativa de las

\footnotetext{
2 "El orden mundial es caníbal, absurdo y mortifero», decía Jean Ziegler en una entrevista de Vicente Romero publicada en el diario El Mundo el 22 de julio de 2014.
} 
instituciones internacionales económico-financieras y los organismos multilaterales, las grandes empresas reenvían sus obligaciones a las legislaciones nacionales, previamente sometidas a la lógica neoliberal; al Derecho Internacional de los Derechos Humanos, caracterizado por su debilidad para ejercer de contrapeso a los abusos cometidos por las compañías multinacionales; así como a la Responsabilidad Social Corporativa (RSC) y los códigos de conducta, instrumentos basados en la voluntariedad y carentes de exigibilidad jurídica para poder obligar a las transnacionales al cumplimiento efectivo de los derechos humanos (Hernández y Ramiro, 2009).

No es de extrañar, en estas condiciones, que el establecimiento de mecanismos de control y de normas vinculantes para las grandes empresas haya sido objeto de numerosos debates, tanto desde la perspectiva estatal como a escala internacional, en las cinco últimas décadas (Martín-Ortega, 2008). El hecho de que en el seno de Naciones Unidas acabe de retomarse - actualizando los debates de los ańos setenta - la propuesta de establecer una normativa internacional de carácter vinculante para obligar a las empresas transnacionales al respeto de los derechos humanos en cualquier parte del mundo ha hecho que, de nuevo, vuelvan a ponerse de actualidad cuestiones centrales como la asimetría que hay entre los derechos de las grandes empresas y sus obligaciones, la necesidad de instaurar mecanismos eficaces para el seguimiento y la evaluación de los impactos generados por las multinacionales, y la urgencia de formular alternativas concretas para controlar las prácticas de estas compañías.

En este contexto, las corporaciones transnacionales han ido poniendo en marcha desde finales de los ańos noventa diferentes estrategias para transmitir al conjunto de la sociedad el mensaje de que, como decía el presidente del BBVA hace unos años, "las empresas más que parte del problema son parte de la solución» (Prandi y Lozano, 2009: 99). Del Global Compact, lanzado en enero de 1999 en el Foro Económico Mundial de Davos con el objetivo de constituirse como "un marco de acción encaminado a la construcción de la legitimación social de los negocios y mercados", a la Cumbre del Clima, que tuvo lugar en diciembre de 2015 en París y concluyó con lo que los mass media presentaron como un "acuerdo histórico" al ser "juridicamente vinculante en todo excepto en los objetivos de emisión de gases de efecto invernadero" ${ }^{3}$, las grandes multinacionales han ido desarrollando diversas estrategias para tratar de ir reposicionando su reputación corporativa e imagen de marca. Todas ellas, en realidad, son complementarias y siguen una línea de continuidad con las estrategias promovidas por las grandes corporaciones y los lobbies empresariales durante las dos últimas décadas.

\footnotetext{
3 Eso decía el diario El País en su editorial, titulado «Un salto decisivo», del 13 de diciembre de 2015 .
} 
Figura 1

Estrategias empresariales

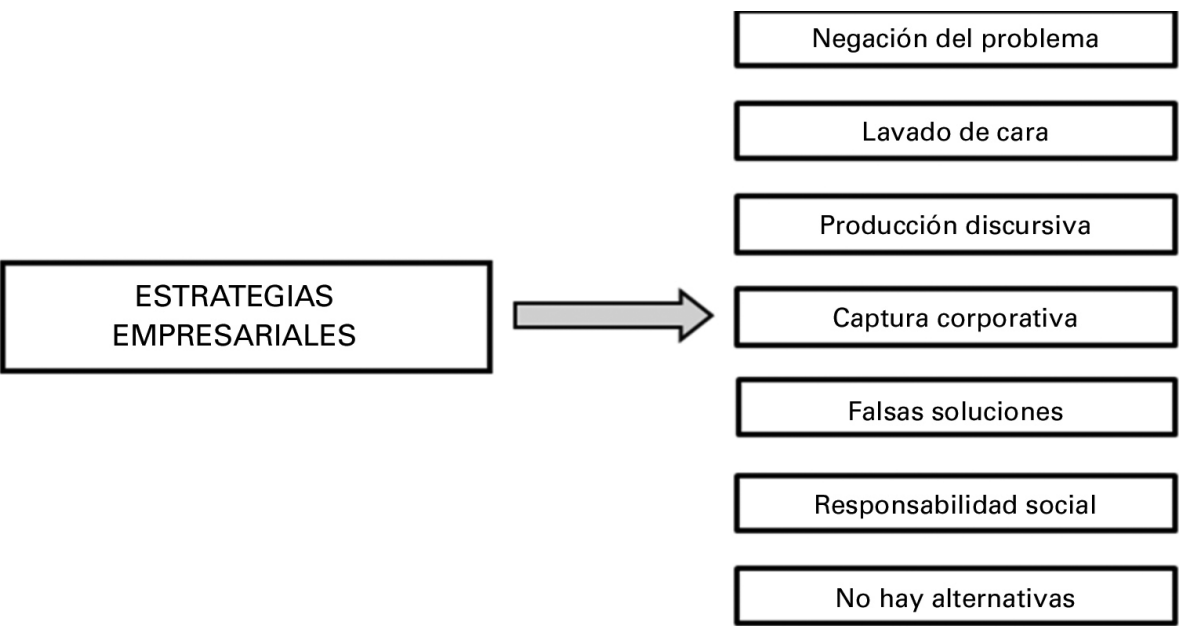

Fuente: Elaboración propia.

Negar el problema ha sido, desde los inicios del capitalismo industrial, la primera de las estrategias empresariales para enfrentar las críticas en su contra. En el caso del calentamiento global, por ejemplo, aunque ahora pueda parecer que sucedió hace mucho tiempo, la realidad es que las empresas transnacionales han estado negando la existencia de la influencia humana en el cambio climático hasta solo hace unos años. No olvidemos las grandes sumas de dinero que una de las mayores multinacionales del planeta, la petrolera Exxon Mobil, invirtió durante la primera década de este siglo en la financiación de estudios que sirvieran para rebatir los argumentos de las instituciones internacionales y las organizaciones ecologistas (Corporate Europe Observatory, 2015). Es lo que algunos autores han denominado "la industria de la cortina de humo de la duda», a la que también se han sumado tabaqueras como Philip Morris y otras grandes compañías (Goodman y Moynihan, 2015). Algo similar ocurrió cuando Naciones Unidas comenzó a prestar atención a cuestiones como la pobreza, la desigualdad y el desarrollo; entonces, las multinacionales negaron sus responsabilidades y trataron de pasárselas a los Estados y a los gobiernos locales.

Las grandes corporaciones, al mismo tiempo, pusieron en marcha un proceso de «lavado de cara» — posiblemente el más conocido sea el greenwashing, esto es, el marketing empresarial que tiene que ver con aspectos medioambientales - que, sin embargo, no ha tenido apenas ninguna traducción práctica en cambios reales en el modus operandi habitual de estas compañías. Se trata, fun- 
damentalmente, de una cuestión de comunicación y publicidad: un contraataque empresarial para recuperar la imagen y reputación corporativas ante los escándalos financieros, desastres ambientales y conflictos laborales en los que muchas multinacionales se han visto implicadas (Klein, 2001). Para ello han contado, incluso, con el aval de instituciones como la propia ONU —es lo que se ha venido a llamar el bluewashing, el «lavado de cara azul»—: numerosas empresas demandadas por violar los derechos humanos, contaminar el medio ambiente, no respetar los derechos laborales y estar involucradas en casos de corrupción disponen hoy del aval de Naciones Unidas, ya que son miembros de pleno derecho del Global Compact.

Crecimiento, empleo, recuperación, riqueza, sostenibilidad... son palabras recurrentes en el relato que tratan de construir los think tanks empresariales como tercera estrategia para avalar las bondades del actual modelo socioeconómico y minimizar las críticas al mismo. Dado que las consecuencias de la expansión global de las transnacionales en el marco del actual modelo socioeconómico han venido siendo profusamente documentadas y sistematizadas por diferentes centros de estudios, organizaciones no gubernamentales y movimientos sociales de todo el mundo (Ramiro y González, 2013) — poniendo en evidencia que la internacionalización de sus negocios conlleva una serie de efectos negativos a nivel social, económico, político, ambiental y cultural (González y Garay, 2014) —, las grandes empresas han optado por llevar a cabo una extensa producción discursiva para contrarrestar el creciente rechazo social que han ido generando. De este modo, las escuelas de negocios y los think tanks vinculados a las compañías multinacionales han elaborado estudios y análisis para vincular la presencia internacional de las empresas transnacionales con el logro de los objetivos de desarrollo que se prometieron para justificar su llegada a los países periféricos - mostrando únicamente los impactos positivos de sus actividades en aspectos como la transferencia de tecnología, la mejora de la provisión de bienes públicos y privados, el incremento del empleo, el acceso de las mujeres al mercado de trabajo y el fomento de la inversión como motor de desarrollo (Olivié, Pérez y Macías, 2011; Ruesga y Casilda, 2008)—, construyendo así un relato con el que no pueda cuestionarse su centralidad en la economía global.

Otra de las estrategias utilizadas por las grandes corporaciones ha sido la penetración en las instituciones internacionales y organismos multilaterales encargadas de marcar la agenda global de desarrollo, lo cual ha tenido lugar tanto a través de la creación de discurso como de la elaboración de normas y políticas. Este proceso de captura corporativa ha venido siendo una constante desde la década de los noventa: desde que en 1927 Rockefeller financiara la biblioteca de la Sociedad de Naciones, que aún hoy sigue funcionando en la sede de la ONU en Ginebra, hasta que hace algo más de quince años Kofi Annan presentara el Global Compact de Naciones Unidas con el aval de las mayores transnacionales del mundo, pasando por todo el fomento de las alianzas público-privadas y los ne- 
gocios inclusivos del que han hecho gala organismos como la ONU en los últimos años (Romero y Ramiro, 2012; Hernández y Ramiro, 2015: 47-83), esta organización multilateral ha sufrido un innegable proceso de cooptación empresarial. Sirva como símbolo el caso del PNUD, que en solo una década pasó de afirmar que «el desarrollo humano es el desarrollo del pueblo, para el pueblo y por el pueblo" a sostener que "los actores del sector privado impulsados por incentivos del mercado tienen capacidad probada para contribuir a importantes metas del desarrollo» (PNUD, 2004: 40).

La producción discursiva y la captura corporativa, asimismo, han ido acompañadas de variadas propuestas de soluciones empresariales en el marco del consenso global sobre el modelo de desarrollo, sin cuestionar en todo caso los mecanismos de apropiación y acumulación de riqueza que están en el centro del sistema socioeconómico realmente existente. En esta línea, muchas son las teorías que desde los principales agentes económicos se han propuesto en los últimos tiempos: capitalismo creativo (Gates, 2008), globalización inteligente (Fundación Rockefeller, 2008: 8-9), desarrollo global 2.0 (Future Trends Forum, 2009: 13) y capitalismo inclusivo (Prahalad y Hart, 2002), entre otras. Con ello, las instituciones que nos gobiernan han optado por seguir avalando la lógica de la autorregulación empresarial — a pesar de que, como ha demostrado el crash de 2008, eso puede tener efectos muy destructivos, incluso para el propio capitalismo- antes que por instaurar mecanismos efectivos para obligar a las grandes compañías a respetar la naturaleza y cumplir los derechos humanos. Por eso, como ha escrito Susan George (2015: 180), «necesitamos normas estrictas $y$ de obligado cumplimiento, asi como una legislación, preferiblemente internacional, que controle la conducta de las empresas, no soluciones aparentes».

\section{Responsabilidad social $v s$. mecanismos de control}

Mientras el cuerpo normativo relacionado con la mercantilización del sistema neoliberal ha ido perfeccionándose a favor de las empresas transnacionales, se ha ido abandonando la posibilidad de ejercer un control real sobre sus actividades, dejando en buena medida sus obligaciones socioecológicas en manos de la RSC y los códigos de conducta. En estos momentos, además, a raíz de la negociación del Tratado Transatlántico de Comercio e Inversiones (TTIP) entre la Unión Europea y Estados Unidos, así como de la firma de una nueva oleada de tratados de libre comercio - entre ellos, el Acuerdo sobre el Comercio de Servicios (TISA, por sus siglas en inglés), que ahora negocian cincuenta países-, con el horizonte de que puedan reforzarse aún más la lex mercatoria y la seguridad jurídica de los contratos de las compañías multinacionales en detrimento de los derechos de las mayorías sociales, resurge la idea de incluir la responsabilidad social como un elemento corrector de esta asimetría normativa. 
Dos décadas después de que se certificara la asunción de la responsabilidad social corporativa como una suerte de salto adelante en el modelo de relaciones entre las grandes empresas y la sociedad, puede constatarse que la RSC no parece ser un instrumento eficaz para controlar a las grandes empresas; se trata de una fórmula de soft law (Derecho blando) para tratar de contener el poder de las transnacionales (Shamir, 2007: 86-101), que se amparan en la ética de los negocios y en la práctica solamente remiten sus obligaciones a sus memorias anuales. $\mathrm{Y}$ es que, de hecho, los programas de RSC y los acuerdos voluntarios no comprometen de manera efectiva a las companías multinacionales, que unilateralmente deciden qué firmar, cómo hacerlo y cómo cumplirlo.

Todo este debate tiene que ver con un concepto, el de la responsabilidad social de las grandes corporaciones, que se había quedado en standby tras el estallido de la crisis financiera en 2008 y la tragedia del Rana Plaza en 2013. Ahora, una vez que se ha comprobado que la autorregulación empresarial ha sido la base del crash global y después de que en Bangladesh murieran más de 1.100 personas en el derrumbe de una fábrica textil que producía para las grandes marcas internacionales, con cada nuevo caso de escándalo o de fraude protagonizado por una corporación transnacional resurge con fuerza una discusión que, de hecho, viene dándose desde hace más de cuatro décadas. Eso sí, como parece que ha quedado en evidencia con el fraude de Volkswagen ${ }^{4}$, de poco sirven los códigos de conducta y los acuerdos voluntarios - como el «histórico acuerdo» de la COP 21 de París - si no hay mecanismos e instancias que controlen efectivamente la manera de operar de las grandes compañías. En palabras de Enrique Dans (2015):

El caso Volkswagen representa, a todos los efectos, el fracaso absoluto de la RSC. No hay paliativos posibles: hablamos de una manipulación consciente, conocida a todos los niveles de la compañía, intencionadamente diseñada para obtener un plus de competitividad con el que hacer frente a la pujanza de otros competidores, y que consiguió poner a la marca en el trono de su industria a nivel mundial al tiempo que se publicitaba como ecológica y envenenaba todo el planeta.

Así las cosas, frente al nuevo Derecho Corporativo Global que han ido construyendo en los últimos cuarenta ańos las grandes corporaciones, los Estados y las instituciones internacionales que las apoyan - a través de todo un sinfín de contratos, tratados comerciales y acuerdos de protección de inversiones, miles de normas en la OMC, el FMI y el Banco Mundial, tribunales internacionales de arbitraje y mecanismos de resolución de disputas inversor-Estado (Hernández, 2009)—, se hace necesario contar con contrapesos suficientes y mecanismos efectivos para el control de sus impactos sobre las personas y el planeta. De

\footnotetext{
${ }^{4}$ La mayor multinacional alemana reconoció a finales de 2015 que había manipulado el software presente en los motores de 11 millones de coches para que pareciera que sus emisiones de gases contaminantes eran mucho menores que las reales.
} 
ahí que, para contrarrestar el poder político, económico y jurídico de las empresas transnacionales y la fuerza de la lex mercatoria, haya de invertirse la pirámide normativa, situando en el vértice los derechos de las mayorías sociales en lugar de los intereses privados de la clase político-empresarial que gobierna nuestras sociedades. De este modo, se hace necesario contar con un nuevo modelo donde las personas y el medio ambiente tengan prioridad sobre los beneficios y los intereses corporativos.

Como se establece en el Mandato de comercio alternativo (VVAA, 2014), el objetivo es que los derechos humanos, los derechos de las mujeres, los derechos indígenas, los derechos laborales y la protección de la naturaleza estén por encima de los intereses empresariales y privados. Y todas estas iniciativas, a su vez, son complementarias de otras como el Tratado internacional de los pueblos para el control de las empresas transnacionales, una herramienta alternativa, elaborada desde el trabajo de los movimientos sociales y las redes de solidaridad internacional, para el ejercicio de un control real sobre las operaciones de las grandes corporaciones, que parte de la siguiente premisa (Hernández, González y Ramiro, 2014: 24):

La actual coyuntura internacional exige decidirse por una de las dos hojas de ruta o vías posibles: profundizar un marco radicalmente distinto, en el que los pueblos y las comunidades presionen hacia un marco obligatorio de control de las transnacionales, o mantener la vía de la voluntariedad condescendiente con las transnacionales y apostar por instrumentos como la responsabilidad social corporativa, el Global Compact y los Principios Rectores, entre otros.

En último término, cuando ninguna de las anteriores estrategias —incluida la RSC como una pretendida variable correctora de las malas prácticas de las empresas transnacionales - les ha resultado exitosa a las grandes corporaciones, estas y las instituciones que las apoyan han recurrido a la idea tantas veces citada de que resulta "más fácil imaginar el fin del mundo que el fin de capitalismo» (Jameson, 2003: 103) y, en esta línea, han tratado de situar en una posición sin salida a quienes puedan poner en duda el discurso dominante. Sin embargo, moviéndose entre la posibilidad de instaurar mecanismos de control para limitar el poder de las fuerzas del mercado y la urgencia de construir propuestas para avanzar en una transición post-capitalista, existen múltiples iniciativas que actualmente se están llevando a cabo para construir otros modelos de economía y sociedad.

\section{Alternativas y propuestas de transición}

Con el objetivo de construir propuestas de transición que sirvan para avanzar hacia economías y sociedades post-capitalistas, estos nuevos discursos e ini- 
ciativas contrahegemónicas van caminando con una triple perspectiva. Primero, con una dinámica de resistencia: investigando y denunciando la expansión del capital transnacional para tratar de frenar sus impactos económicos, políticos, sociales, ambientales y culturales. Segundo, en base a una lógica de regulación: formulando mecanismos de control y propuestas de redistribución que, en el marco del actual modelo socioeconómico, sirvan para poner los derechos de las personas y los pueblos, como mínimo, al mismo nivel que esa lex mercatoria que protege con fuerza los negocios de las grandes empresas. Y tercero, con la idea de apostar por la construcción de alternativas: impulsando y poniendo en práctica propuestas concretas que, teniendo como horizonte la necesidad de construir modelos de desarrollo y de sociedad diferentes al dominante, vayan arańando, aquí y ahora, parcelas de autonomía y soberanía económica a las empresas transnacionales.

Estas dinámicas de resistencia, regulación y alternativa están avanzando a un mismo tiempo, en paralelo y de forma dialéctica; todo ello, en el marco de una lógica de proceso y con una perspectiva de transición. Puede decirse que, en este contexto, las tres perspectivas son complementarias y todas ellas, a la vez, interpelan a gobiernos, empresas y organizaciones sociales a establecer otros sistemas socioeconómicos que no tengan como pilar fundamental lo que Polanyi (1989: 66) denominó — refiriéndose a los orígenes del capitalismo y constatando cómo "en el espacio de una generación toda la tierra habitada se vio sometida a su corrosiva influencia»— "el móvil de la ganancia»5.

Las dinámicas de resistencia y de contestación social para enfrentar el dominio del capital sobre la vida en el planeta vienen produciéndose, en realidad, desde que las grandes corporaciones - que, al principio, fueron fundamentalmente estadounidenses y, más tarde, también europeas y asiáticas - se dedicaron a expandir sus operaciones a otros países para profundizar con su lógica de crecimiento y acumulación. Puede decirse, entonces, que hay una especie de hilo rojo que conecta las luchas del movimiento obrero a finales del siglo xix y comienzos del xx, con sus reclamaciones de mejoras en las condiciones laborales y en el reparto de los beneficios empresariales, con las que hoy tienen como protagonistas a las comunidades locales y pueblos indígenas que se oponen a la presencia de mineras y petroleras en sus territorios, pasando por todas las campañas de resistencia que tuvieron lugar a lo largo del siglo pasado frente a empresas como United Fruit Company — hoy llamada Chiquita Brands_-, Nestlé, Shell, Nike, McDonald's, Coca-Cola, Chevron-Texaco y muchas otras transnacionales (González y Ramiro, 2013).

5 Como escribió Karl Polanyi en La gran transformación, "el mecanismo que el móvil de la ganancia puso en marcha únicamente puede ser comparado por sus efectos a la más violenta de las explosiones de fervor religioso que haya conocido la historia». 
Figura 2

Propuestas de transición
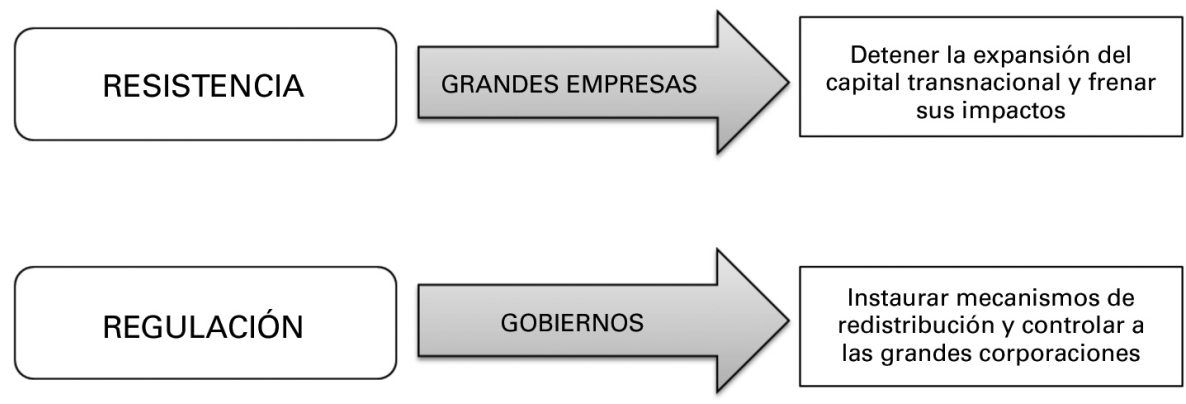

Instaurar mecanismos de redistribución y controlar a las grandes corporaciones
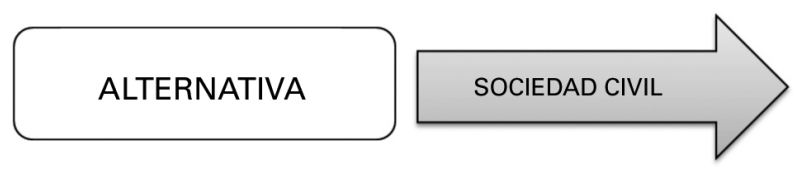

Construir propuestas alternativas concretas para una economía post capitalista

Fuente: Elaboración propia.

Estos procesos de resistencia se dirigen, sobre todo, a las grandes corporaciones, con el objetivo de detener o, al menos, minimizar sus impactos directos sobre las poblaciones y el entorno. En ellos, el movimiento obrero y las organizaciones sindicales, que históricamente han jugado un papel central en la consecución de derechos laborales y sociales, ya no son los únicos agentes de las reivindicaciones. De hecho, como la interacción de las transnacionales con el conjunto de la sociedad no se limita exclusivamente al plano laboral, muchas de estas nuevas formas de acción colectiva — unas, con una fuerte componente de movilización social; otras, con una más acusada vertiente de denuncia e incidencia política- han sido impulsadas por las personas y los colectivos que se han visto más directamente afectados por los impactos de estas empresas: usuarios, consumidores, campesinas, indígenas, precarios, desempleadas, activistas, etc.

En el caso concreto de América Latina, además, estos procesos de resistencia popular frente al capital transnacional resultaron decisivos a la hora de contribuir a la conformación de las mayorías sociales que, conforme fue avanzando la primera década de este siglo, desalojaron de los gobiernos a los gestores del Consenso de Washington y certificaron el fin de «la larga noche neoliberal». Ese es el caso de Bolivia, por ejemplo, donde no podría entenderse el triunfo electoral de Evo Morales hace una década sin tener en cuenta el intenso ciclo de movilizaciones que se produjo en el país en los años precedentes, aquellos que transcurrieron entre lo que se ha conocido como la guerra del agua y la guerra 
del gas (González y Gandarillas, 2010). Eso sí, estos gobiernos que de una u otra manera apuestan por la transformación de de las estructuras de poder, superada o amortiguada la etapa de resistencia, se debaten posteriormente en una dualidad: optar por una asociación táctica con las corporaciones transnacionales, que pueda suponer un avance en términos de regulación, o por una apuesta estratégica por un modelo de desarrollo que sirva para la construcción de una propuesta alternativa y esté basado en paradigmas como el decrecimiento, el buen vivir o el ecofeminismo.

En realidad, en esa tensión continua entre regulación y alternativa, entre la instauración de mecanismos de control para reducir el poder corporativo y la puesta en marcha de propuestas concretas para avanzar en una transición postcapitalista, es justamente donde se están moviendo la mayoría de las iniciativas que le están disputando la centralidad del modelo socioeconómico a las grandes empresas. Y como apenas existen espacios que no hayan sido colonizados por la lógica de la propiedad privada y el crecimiento económico, buena parte de estas experiencias funcionan mediante una combinación de esa doble perspectiva de regulación y alternativa.

Así, como parte de una misma propuesta de transición, se trata de combinar las exigencias tanto de mejorar la legislación existente como de crear nuevas normativas a nivel nacional e internacional - en términos de transparencia y rendición de cuentas, de evaluación y seguimiento de las prácticas de las grandes compañías, de una fiscalidad justa que subordine los beneficios empresariales al cumplimiento efectivo de los derechos humanos, etc.-, que estén dirigidas a los gobiernos e instituciones multilaterales, con la puesta en práctica de proyectos alternativos que, partiendo de renovados paradigmas que no tengan como principio fundamental el móvil de la ganancia, sean impulsados por las organizaciones de la sociedad civil para ir caminando hacia nuevos horizontes emancipatorios que pongan la diversidad, la colectividad, la democracia y la sostenibilidad de la vida en el centro.

Ambas vías se relacionan de forma dialéctica, teniendo presente que, como afirma Miren Etxezarreta (2014: 11-12), «no es lo mismo una propuesta, un medio, un instrumento alternativo para resolver un problema especifico, que una sociedad alternativa que tiene por objetivo subvertir la existente». Y, además, se construyen dentro de una lógica de proceso, sabiendo que, citando palabras de esta misma autora, "la alternativa es el propio proceso de lucha y transformación, un proceso que se tiene que ir construyendo en la vida cotidiana, en la lucha por una sociedad diferente».

Es en este contexto en el que diferentes organizaciones y movimientos sociales, el Tribunal Permanente de los Pueblos, numerosos expertos y activistas han propuesto alternativas concretas para controlar las prácticas de las empresas transnacionales. Dirigidas a los distintos actores clave de la lex mercatoria -Es- 
tados, grandes corporaciones, instituciones internacionales, tribunales de arbitraje-, estos mecanismos de control y estas propuestas alternativas se enfocan tanto en la mejora de las legislaciones nacionales como, sobre todo, en la creación de nuevos procedimientos e instancias a escala internacional. En este sentido, la aprobación de un código vinculante, la creación de un tribunal internacional que juzgue a las empresas transnacionales y la creación de un centro para el seguimiento de las mismas son algunas de las ideas fuerza sobre las que se construyen las propuestas alternativas de la sociedad civil. Asimismo, la exigencia de obligaciones extraterritoriales a las grandes corporaciones y de coherencia de políticas a las administraciones públicas, junto con una apuesta de los gobiernos municipales, autonómicos y estatales por las cláusulas sociales y ambientales, los mecanismos de redistribución económica y reequilibrio territorial, y las medidas de remunicipalización y nacionalización de ciertas empresas presentes en sectores estratégicos, entre otras, son algunas de las posibles iniciativas que podrían ser desarrolladas en esta línea (Hernández y Ramiro, 2015: 89-146).

Figura 3

Propuestas y alternativas

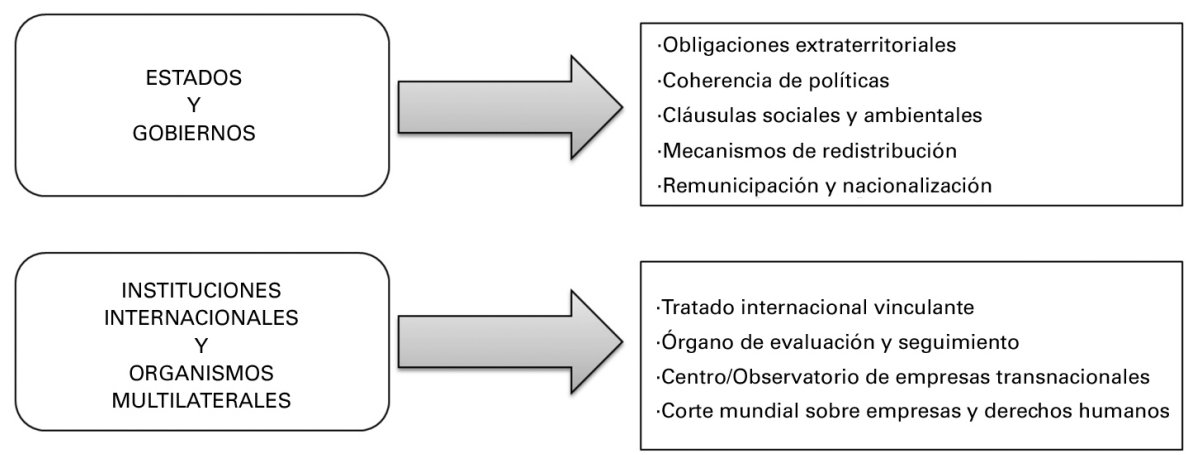

Fuente: Elaboración propia.

Empresas recuperadas, monedas sociales, finanzas solidarias, banca ética, comercio justo, cooperativas de consumo agroecológico, proyectos de vivienda comunitaria en derecho de uso, cooperativas de trabajo asociado, empresas de inserción, circuitos cortos de comercialización... Todos ellos son ejemplos, cada uno en distinto grado y con diversa potencialidad, de cómo es viable organizar las actividades humanas de otra manera, al margen de la lógica de la acumulación capitalista. En este sentido, mientras algunas de ellas ya están contribuyendo a disputarle parcelas de poder y áreas del mercado a las compañías multinacionales, otras están en una fase más incipiente y se constituyen como laboratorios de experiencias que, a una escala sensiblemente menor, sirven para 
ensayar prácticas social y ambientalmente responsables, basándose en los principios de la economía solidaria, feminista y ecológica. "De tener éxito, estas pequenas experiencias crearán los nodos de agregación y copia para la siguiente fase. Los "faros imprescindibles", los "bancos de prueba", dicen los autores de En la espiral de la energía.

El reto, en este contexto, está en cómo seguir articulando alternativas reales y viables que sirvan para continuar con el diseño de otras maneras de entender la economía. Existe una multitud de movimientos sociales que tratan de superar la economía capitalista y el Estado como pilares inmutables de la organización social, y para ello están buscando alternativas basadas en la solidaridad, la proximidad y la participación. Como las que se encuadran, por ejemplo, en la economía solidaria, que

frente a la lógica del capital, la mercantilización creciente de las esferas públicas y privadas, y la búsqueda de máximo beneficio, persigue construir relaciones de producción, distribución, consumo y financiación basadas en la justicia, cooperación, la reciprocidad, y la ayuda mutua (Pérez-Mendiguren, Etxezarreta y Guridi, 2009: 13).

En esa misma dirección, la democracia radical y las necesidades humanas aparecen como factores clave para una nueva organización socioeconómica, en la que se subordinen las dimensiones productiva y financiera de la economía a las personas y al cuidado de la vida en el planeta. Todo ello, tal y como recoge el nuevo mandato de comercio alternativo (VVAA, 2014: 323), siempre en base a una premisa central:

Los derechos humanos, la democracia y la transparencia deben priorizarse por encima de los intereses empresariales y privados, al igual que el acceso universal a los servicios públicos de calidad, la protección social, las normas laborales y ambientales.

\section{Bibliografía}

CORPORATE EUROPE OBSERVATORY (2015): Bruselas, las grandes empresas energéticas y las puertas giratorias: un hervidero para el cambio climático, Ámsterdam.

DANS, Enrique (2015): «Volkswagen and the failure of Corporate Social Responsibility», Forbes, 27 de septiembre.

ETXEZARRETA, Miren (2014): «Reflexionando sobre las alternativas», Dossieres EsF, n. ${ }^{\circ} 13$.

FERNÁNDEZ, Gonzalo (2015): «Alternativas para disputar el poder, el ser y el saber a las transnacionales", Pueblos, n. ${ }^{\circ} 66$.

FERNÁNDEZ, Ramón y GONZÁLEZ, Luis (2014): En la espiral de la energía, Libros en Acción y Baladre, Madrid, vol. 2.

FUNDACIÓN ROCKEFELLER (2008): Smart Globalization: Benefiting More People, More Fully, in More Places, Nueva York. 
FUTURE TRENDS FORUM (2009): Innovación social. Reinventando el desarrollo sostenible, Fundación de la Innovación Bankinter.

GATES, Bill (2008): "A New Approach to Capitalism in the 21st Century», Foro Económico Mundial, Davos (Suiza), 24 de enero.

GEORGE, Susan (2015): Los usurpadores. Cómo las empresas transnacionales toman el poder, Barcelona, Icaria.

GONZÁLEZ, Erika y GANDARILLAS, Marco (coords.) (2010): Las multinacionales en Bolivia. De la desnacionalización al proceso de cambio, Icaria, Barcelona.

GONZÁLEZ, Erika y GARAY, Ane (coords.) (2014): Empresas transnacionales e impactos en América Latina: 4 estudios de caso en El Salvador, Colombia y Bolivia, Cuadernos OMAL, n. ${ }^{\circ} 7$.

GONZÁLEZ, Erika y RAMIRO, Pedro (2013): «Resistir a las transnacionales. Los movimientos sociales frente a las grandes corporaciones en Europa y América Latina», en HERNÁNDEZ, Juan; DE LA FUENTE, Mikel; DE VICENTE, Andrea e IRURZUN, Koldo (eds.), Empresas transnacionales en América Latina: Análisis y propuestas del movimiento social y sindical, Bilbao, Universidad del País Vasco, Hegoa y OMAL.

GOODMAN, Amy y MOYNIHAN, Denis (2015): «Negación del cambio climático: la industria de la cortina de humo de la duda", La Marea, 3 de enero.

HARVEY, David (2004): El nuevo imperialismo, Madrid, Akal.

HERNÁNDEZ, Juan (2009): Las empresas transnacionales frente a los derechos humanos. Historia de una asimetría normativa, Bilbao, Hegoa y OMAL.

HERNÁNDEZ, Juan y RAMIRO, Pedro (2009): El negocio de la responsabilidad. Crítica de la Responsabilidad Social Corporativa de las empresas transnacionales, Barcelona, Icaria.

HERNÁNDEZ, Juan y RAMIRO, Pedro (2015): Contra la «lex mercatoria». Propuestas y alternativas para desmantelar el poder de las empresas transnacionales, Barcelona, Icaria.

HERNÁNDEZ, Juan; GONZÁLEZ, Erika y RAMIRO, Pedro (eds.) (2012): Diccionario critico de empresas transnacionales, Barcelona, Icaria.

HERNÁNDEZ, Juan; GONZÁLEZ, Erika y RAMIRO, Pedro (2014): Tratado internacional de los pueblos para el control de las empresas transnacionales. Una apuesta desde los movimientos sociales y la solidaridad internacional, Cuadernos de Trabajo / Lan Koadernoak, Hegoa, UPV/EHU, n. ${ }^{\circ} 64$.

JAMESON, Fredric (2003): «La ciudad futura», New Left Review, n. ${ }^{2}$ 21, Akal.

KLEIN, Naomi (2001): No Logo. El poder de las marcas, Barcelona, Paidós.

MARTÍN-ORTEGA, Olga (2008): Empresas multinacionales y derechos humanos en Derecho Internacional, Barcelona, Bosch Internacional.

OLIVIÉ, Iliana; PÉREZ, Aitor y MACÍAS, Carlos M. (2011): Inversión Directa Extranjera y desarrollo: recomendaciones a la cooperación española, Madrid, Real Instituto Elcano.

PÉREZ-MENDIGUREN, Juan Carlos; ETXEZARRETA, Enekoitz y GURIDI, Luis (2009): Economía social, empresa social y economía solidaria: diferentes conceptos para un mismo debate, Papeles de Economía Solidaria n. ${ }^{\circ}$ 1, REAS Euskadi.

PNUD (2004): El impulso del empresariado. El potencial de las empresas al servicio de los pobres, Comisión sobre Sector Privado y Desarrollo, Naciones Unidas.

POLANYI, Karl (1989): La gran transformación, Madrid, La Piqueta.

PRAHALAD, C.K. y HART, S.L. (2002): "The fortune at the bottom of the pyramid», Strategy and Business, n. ${ }^{\circ} 26$. 
PRANDI, Maria y LOZANO, Josep M. (eds.) (2010): La RSE en contextos de conflicto y postconflicto: De la gestión del riesgo a la creación de valor, Barcelona, Escuela de Cultura de Paz (UAB) y ESADE.

RAMIRO, Pedro (2014): Marca España. ¿A quién beneficia?, Barcelona, Icaria.

RAMIRO, Pedro y GONZÁLEZ, Erika (2013): «Empresas transnacionales: impactos y resistencias», Ecologista, n. ${ }^{\circ}$ 77, pp. 18-21.

ROMERO, Miguel y RAMIRO, Pedro (2012): Pobreza 2.0. Empresas, estados y ONGD ante la privatización de la cooperación al desarrollo, Barcelona, Icaria.

RUESGA, Santos M. y CASILDA, Ramón (dirs.) (2008): Impactos de las inversiones españolas en las economías latinoamericanas, Madrid, Marcial Pons.

SHAMIR, Ronen (2007): «La responsabilidad social empresarial: un caso de hegemonía y contrahegemonía», en SOUSA, Boaventura y RODRÍGUEZ, César A. (eds.), El derecho y la globalización desde abajo. Hacia una legalidad cosmopolita, Barcelona, Anthropos.

TEITELBAUM, Alejandro (2010): La armadura del capitalismo, Barcelona, Icaria.

VVAA (2014): Mandato de comercio alternativo. Por una nueva perspectiva frente al comercio, Bruselas. 